\title{
O TEMPO E O ESPAÇO DA CIÊNCIA DA INFORMAÇÃO
}

\author{
Aldo de Albuquerque BARRETO ${ }^{1}$
}

\section{RESUMO}

O artigo lança um olhar sobre o desenvolvimento do campo da ciência da informação e ao seu relacionamento com a tecnologia. As mudanças na tecnologia da informação, ocorridas nos últimos 50 anos, reorganizam e ordenam as atividades associadas à Ciência da Informação. O modelo tecnológico inovador é fechado e não permite dúvidas ou contestação. Nesta ambiência, são considerados o presente e o futuro da área, as modificações no tempo e no espaço da informação em relação ao receptor. O papel do fluxo de informação, das estruturas de informação, do profissional da área e dos objetivos da Ciência da Informação são delineados a partir da crença em que a realidade se divide em três mundos: o subjetivo, o material e o do ciberespaço.

Palavras-chave: Ciência da Informação; História; Tecnologia da Informação.

\begin{abstract}
The article launches a glance in the development of Information Science and in its relationship with its technologies. The changes in the information technology that happened in the last 50 years, organize and gave order to all the activities associated with Information Science. The model of technological innovation is closed and it does not allow for doubt or questions. In this environment the present and the future of Information Science are analyzed. The role of the flow of information, of the structures of information, of the professional of the area and the objectives of Information Science are delineated starting from the faith in that, the reality is divided in three worlds: the subjective, the material and the one of the cyberspace.
\end{abstract}

Key words: Information Science; History; Information Technology.

\section{INTRODUÇÃO}

A Ciência da Informação teve seu aparecimento e expansão no após-guerra, principalmente a partir de 1950, quando pesquisas e documentos mantidos fora do fluxo normal de informação foram liberados para o conhecimento coletivo. No limiar do período de pós-guerra, entre 1945 até 1948, uma bolha tecnológica nos deu: a fissão nuclear que produziu a primeira bomba atômica; foi desenvolvido o Eniac e depois o Univac-1, os primeiros computadores de aplicações gerais; Fleming desco-

1. Pesquisador Titular MCT/Ibict. Presidente da ANCIB (Associação Nacional de Pesquisa e Pós Graduação em Ciência da Informação). 
briu com ajuda de outros cientistas a Penicilina em um segundo andar do Hospital St. Mary"s em Londres; foi fabricado o avião de vôo mais rápido do que o som; foi inventado o transistor; foi fundada a Unesco; Norbert Wainer publicou "Cybernetics" e discursou sobre a teoria matemática da informação e Vannevar Bush publicou "As we may think".

A grande crise da época era, então, como lidar com o enorme volume de informação disponibilizada, utilizando-se os mecanismos e tecnologias acessíveis. Era necessário gerenciar e controlar o grande volume de informação, estocar e caracterizar seu conteúdo, priorizar o seu uso de acordo com as diferentes comunidades informacionais e promover uma divulgação seletiva e retrospectiva para evitar a duplicação do esforço de pesquisa e permitir que a sociedade conhecesse os avanços que haviam sido efetivados. A conceituação das Leis da Genética de Mendel ficou perdida para o mundo por uma geração, pois sua publicação não se tornou conhecida pelos pesquisadores que poderiam promover a sua continuação e expansão ${ }^{2}$. Grande parte das pesquisas realizadas nas duas décadas subseqüentes a 1950 foram para tentar resolver esses problemas.

Contudo, de uma maneira geral, a interação entre o receptor e os estoques disponíveis de informação era sempre mediada por um profissional da informação; o tempo de retorno da informação solicitada estava na dependência das características internas de eficácia das unidades de informação que hospedavam os estoques; o fluxo da informação era unidirecionado; o receptor tinha acesso a um estoque de cada vez e avaliava a relevância de sua busca, nesse estoque, orientado sempre pelo mediador, em uma condição ex-post.

A crise inicial da Ciência da Informação, se não foi resolvida, foi bastante minorada pelo computador trinta anos após, por volta de 1980. A atual crise que se acerca da Ciência da Informação é mais profunda.
Nestes quase 50 anos que se passaram, desde o artigo de Vannevar Bush, a área não acompanhou a mudança radical que se operou e continua resistindo às modificações provocadas pela microeletrônica, pela telecomunicação e suas técnicas acessórias, nas relações do tempo e espaço da informação.

As mudanças na tecnologia da informação, ocorridas durante os últimos anos, reorganizaram todas as atividades associadas à ciência da informação. A sociedade sempre foi mais afetada pelas transformações, ou pela natureza da tecnologia do que pelo seu conteúdo, pelo menos a curto prazo. Aqueles que convivem mais de perto com essas alterações enfrentam com maior carga as conseqüências sociais e físicas de uma enorme ansiedade tecnológica.

O profissional desta área foi precipitado em uma conjunção de transformações, muitas delas ainda nem mesmo percebidas.

O modelo tecnológico inovador é tão fechado que induz a um distanciamento alienante sobre como ele opera ou se opera no melhor sentido. Se o discurso da ciência traz promessa da verdade, o da técnica traz consigo uma promessa de melhoria das condições do homem, de conforto material, de felicidade. No caso das tecnologias de informação, se o seu objetivo é promover o acesso à informação da maior parte da sociedade, e se esta é uma decisão da autoridade tecnológica, esta é uma condição fechada e avaliada. Não é passível de dúvida ou contraposição, sob pena de insurreição contra o avanço tecnológico, de ser uma atitude retrógrada e ultrapassada com a tecnologia.

A autoridade tecnológica julga e condena quem quer se introduzir no conhecimento do processo. Não cabe questionar ou tentar compreender como uma informação é transmitida via Internet. $\mathrm{O}$ conhecimento interno da técnica é irrelevante e até indesejável. Se as suas conseqüências são benéficas para a sociedade, questionar é quase pouco decente.

2. BUSH, Vanevar. Atlantic Montly, n. 1, July, 1945, pp. 101-108. 


\section{Tempo-Espaço}

A chegada da sociedade eletrônica de informação modificou drasticamente a delimitação de tempo e espaço da informação. A importância do instrumental da tecnologia da informação forneceu a infra-estrutura para modificações, sem retorno, das relações da informação com seus usuários.

As transformações associadas à interatividade e interconectividade no relacionamento dos receptores com a informação, mostram como tempo e espaço modificam as relações com o receptor:

a. interatividade ou inter-atuação multitemporal representa a possibilidade de acesso em tempo real, o que reduz o tempo de acesso pelo usuário a diferentes estoques de informação a quase zero; possibilita o acesso em múltiplas formas de interação entre o usuário e a própria estrutura da informação contida nesse espaço. A interatividade modifica o fluxo: usuário - tempo - informação. Reposiciona os acervos de informação, o acesso à informação e a sua distribuição. O próprio documento de informação se torna mais acessível, pois libera o receptor dos diversos intermediários que executavam funções em linha e em tempo linear, passando para um acesso online e com linguagens interativas; a interatividade e o tempo real libertam o indivíduo dos seus rituais de sincronismo cotidiano: todos executando a mesma atividade e ao mesmo tempo: (ir ao banco, ir ao trabalho, ir ao mercado, ir a aula).

O mais interativo instrumento de comunicação é o telefone, o menos interativo o livro e o periódico. Contudo, a interatividade não está diretamente relacionada à qualidade da informação. Existem diferentes graus de interatividade dependendo de: (a) as possibilidades de apropriação e personalização da mensagem recebida; (b) a reciprocidade das trocas estabelecida na comunicação.

\section{b. inteconectividade - A interconectividade} reposiciona a relação usuário - espaço - informação; opera uma mudança estrutural no fluxo de informação que se torna multiorientado. Quando o tempo se aproxima de zero e a velocidade do infinito, os espaços se desterritorializam, perdem seus limites; a interconectividade dá ao individuo a condição de contigüidade, onde a possibilidade de vizinhança se estende para a região do infinito e permite ao usuário da informação ter a possibilidade de deslocar-se, segundo sua vontade, de um espaço de informação para outro espaço de informação, de um estoque de informação para um outro estoque de informação. $\mathrm{O}$ usuário passa a ser o seu próprio mediador na escolha de informação, o determinador de suas necessidades. Passa a ser o julgador da relevância do documento que procura e do estoque que o contêm, em tempo real, tempo igual a zero, como se estivesse colocado virtualmente dentro do sistema de armazenamento e recuperação da informação.

Essas mudanças operadas no status tecnológico das atividades de armazenamento e transmissão da informação vêm trazendo mutações contínuas, também na relação da informação com seus usuários, com seus intermediários, com a pesquisa e com o ensino em Ciência da Informação. Destacamos como instabilidades mais notáveis, os seguintes pontos:
a. mudanças na estrutura de informação;
b. mudanças no fluxo de informação;
c. o profissional da informação.

\section{A MUDANÇA NA ESTRUTURA DE INFORMAÇÃO ${ }^{3}$}

A interação em tempo real com a estrutura da informação tem questionado o caráter alfabético e linear do documento texto. O computador permite uma liberdade de interação com o texto, livre das amarras da composição e da interpretação linear. O código lingüístico comum permanece como base das estruturas de informação, como um elemento sistemático e compulsório para uma determinada comunidade lingüística (ou de informação), mas a mensagem é individual, intencional e intentada. A mensagem é arbitrária e contingente, o código é anônimo e não intentado. ${ }^{4}$

\footnotetext{
3. Por estrutura de informação entendemos ser a disposição, a forma de organização que assumem as inscrições de informação. 4. RICOEUR, P. Teoria da Interpretação, Edições 70, Lisboa, 1976, 109 p.
} 
A estrutura da informação, como mensagem, se direciona particularmente a cada receptor incluindo em sua formação novas linguagens, como o som e a imagem. Um documento em hipertexto permite, em casos específicos, que cada receptor modifique a mensagem segundo seus conceito de importância com que valoriza o documento, não sendo mais somente leitor mas, atuando como se fosse mais um autor do texto. Nas palavras sedutoras de Levy ${ }^{5}$ uma nova superlinguagem pode estar se formando: "O alfabeto foi inventado em uma época em que não existiam os gravadores de som. Na Antiguidade e na Idade Média os textos alfabéticos eram usados como fitas magnéticas gravadas, porque o homem tinha que ler em voz alta e ouvir o som para obter o significado"

\section{O FLUXO DE INFORMAÇÃO}

O fluxo da informação entre os estoques ou espaços de informação e os usuários permeiam dois critérios: o da tecnologia da informação que almeja possibilitar o maior e melhor acesso à informação disponível e o critério da Ciência da Informação, que intervém para, também, qualificar este acesso em termos das competências para assimilação da informação, como sendo uma condição, que deve ter o receptor da informação acessada: elaborar a informação para seu uso, seu desenvolvimento pessoal e dos seus espaços de convivência. Não é suficiente unicamente, que a mensagem esteja intencionalmente dirigida ao acesso, mas que a mensagem atinja as geografias semânticas do receptor, compatíveis com a sua compreensão e aceitação. Esta é uma diferenciação de mérito para se definir os objetivos, a pesquisa e o ensino na área de Ciência da Informação. As duas premissas deveriam certamente marchar em conjunto, mas a ansiedade tecnológica imprime um posicionamento diferenciado entre as atividades ditas práticas e atividades teóricas no encaminhamento da questão.

Nas décadas iniciais, as unidades de informação trabalhavam com um fluxo de informação realizado em um tempo linear, mensurável e direcionado a um único espaço de informação. Hoje, com a informação on-line, em tempo real, os fluxos de informação multidirecionados podem ser virtuais quando o tempo se aproxima de zero, a velocidade se acerca do infinito e os espaços são de vivência pela não presença.

\section{O FLUXO INTERNO E OS FLUXOS EXTREMOS DA INFORMAÇÃO}

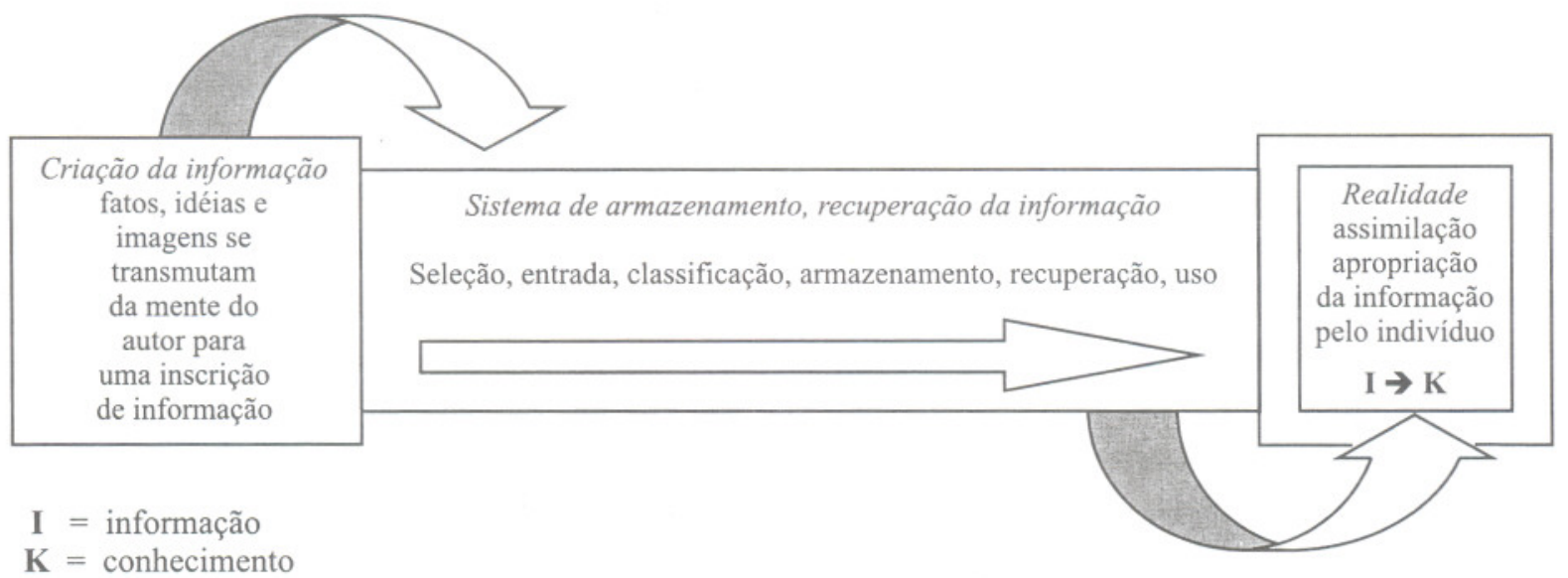

5. LEVY, P. Towards a Superlanguage, (sem data), disponível em www.uiah.fr/bookshop/isea_proc/nextgen/01.html [12.12.97], traduzido por este autor. 
Consideramos que os fluxos de informação se movem em dois níveis: no primeiro nível, os fluxos internos de informação se movimentam entre os elementos de um sistema, que se oriente para sua organização e controle, este fluxo já foi bastante estudado e relatado e possui uma racionalidade técnica e produtivista como premissa. Com isso indicamos que, para a sucessão de eventos, existe um esboço técnico sedimentado, que já foi apropriado há mais de cinqüenta anos, mudando só por algumas adaptações ao mudar da tecnologia. A premissa racional é também produtivista, pois tem como condição de eficiência maximizar o uso dos espaços de armazenagem para minimizar custos. A estes espaços de armazenamento chamamos de estoques de informação, um elo indispensável ao processo de geração de conhecimento mas que por si só nunca são responsáveis pela ação de conhecimento. O fluxo interno se agrega por uma premissa de razão prática, em um campo de ação que permite tomar decisões e um agir baseado em princípios. É o mundo do gerenciamento e controle da informação.

Os fluxos de informação de segundo nivel são aqueles que acontecem nas extremidades do fluxo interno, de seleção, armazenamento e recuperação da informação.Os fluxos extremos são aqueles que por sua atuação mostram a Essência ${ }^{6}$ do fenômeno de transformação, entre a linguagem do pensamento de um emissor $\rightarrow$ è a linguagem de inscrição do autor da informação $\rightarrow$ e o conhecimento elaborado pelo receptor em sua realidade.

Assim, na extremidade esquerda do fluxo interno, e agora não se trata apenas de uma premissa técnica mas da promessa, da esperança da transformação da informação gerada pelo autor para um conhecimento assimilado pelo receptor.

No outro extremo do fluxo interno se realiza um novo fenômeno de informação, cuja Essência está no força da passagem de uma experiência, um fato ou uma idéia que está delineada em uma linguagem de pensamento do agente criador, para uma inscrição de informação é o local onde um autor esboça sua narrativa transformada em um texto expresso em uma linguagem de edição.

\section{O HOMEM DE INFORMAÇÃO: O TRABALHO EM CIÊNCIA DA INFORMAÇÃO}

"Eu só amo aqueles que sabem viver como que se extinguindo, porque são esses os que atravessam de um para o outro lado. "7

As palavras citadas são uma referência de posicionamento para o trabalhar com a informação. O profissional desta área se encontra, nesta atualidade, em um ponto entre o passado e o futuro. Convive com tarefas e técnicas tradicionais de sua profissão mas precisa atravessar para uma outra realidade, onde estão indo seus clientes e aprender a conviver com o novo e o inusitado, numa constante renovação da novidade.

Toda realidade se reduz a três mundos: o mundo subjetivo dos sistemas cerebrais, o mundo objetivo dos sistemas materiais e o e o mundo dos sistemas simbólicos cibernéticos e informatizados. ${ }^{8}$ Em nossa interpretação, a realidade subjetiva dos conteúdos de informação, da sua geração e assimilação, a realidade objetiva dos seus equipamentos e seus instrumentos, e a realidade do ciberespaço ${ }^{9}$, de tempo zero, da existência pela não presença ${ }^{10}$, da realidade virtual conforme o mundo.

Os que trabalham com a informação, ou continuarão a operacionalizar tarefas cotidianas em uma única realidade, e ainda o farão por alguns anos, ou estão se preparando para operar nas três realidades, como uma ponte do passado do hoje para o futuro. Será um profissional vespertino se decidir não realizar a travessia.

\footnotetext{
6. Essência - ação com vigor de propósitos; a estrutura em que vigora; onde o fenômeno desenvolve a força de seu vigor. Escreve-se o E em maiúscula para diferenciar de essência ,com natureza.

7. NIETZSCHE, F. Assim Falava Zaratustra, Editora Tecnoprint S.A, Rio de Janeiro, [sem data], primeira parte, Preâmbulos, negritos deste autor.

8. Carneiro Leão, E. Desafios da Informatização em A Máquina e Seu Avesso, Francisco Alves, Rio de Janeiro, 1987,143 p.

9. Ciberespaço - espaço dos sistemas naturais e artificias harmonizados pela comunicação. A região conjunta de encontro de humanos e do computador, onde seus espaços coincidem.

10. Presença - o estar uma coisa ou pessoa em um lugar determinado.
} 


\section{O OBJETO DE ESTUDO DA CIÊNCIA DA INFORMAÇÃO}

Objetivos bem definidos, para uma área de estudos norteiam todo o pensamento subseqüente em sua estruturação. Orientam sua pesquisa, o seu ensino, delimitam suas fronteiras, as inter-relações com outras disciplinas e o seu núcleo temático.

Neste final de século e devido à sua interação com uma tecnologia intensa, a ciência da informação redefine o conteúdo e a prioridade de seus objetivos continuamente. Há cinco anos atrás seria difícil ver como um dos objetivos da Ciência da Informação o estudo de bibliotecas virtuais, periódicos científicos nascerem online, correio eletrônico. Um novo mundo de informação se avizinha, o da realidade virtual com a tele-imersão, que será um importante foco de estudo desta área.

Assim, alguns objetivos ou são enunciados ou podem ser deduzidos. As pesquisas apresentadas nas Reuniões Nacionais da Ancib, a associação nacional de pesquisa e pós-graduação da área, permitem uma observação, senão dos objetivos mas do refletir da Ciência da Informação:

\section{NÚCLEOS DE PESQUISA EM CIÊNCIA DA INFORMAÇÃO}

\begin{tabular}{|l|c|c|c|}
\hline \multicolumn{1}{|c|}{$\begin{array}{c}\text { Grupos } \\
\Downarrow\end{array}$} & $\begin{array}{c}\text { Enancib } \\
\mathbf{1 9 9 5} \\
\text { Valinhos }\end{array}$ & $\begin{array}{c}\text { Enancib } \\
\mathbf{1 9 9 7} \\
\text { Rio }\end{array}$ & $\begin{array}{c}\text { Enancib } \\
\mathbf{2 0 0 0} \\
\text { Brasília }\end{array}$ \\
\hline Informação e Contexto & $38 \%$ & $27 \%$ & $17 \%$ \\
\hline Organização da informação: & $31 \%$ & $24 \%$ & $36 \%$ \\
\hline Informação Tecnológica & $20 \%$ & $22 \%$ & $23 \%$ \\
\hline $\begin{array}{l}\text { Novas tecnologias de } \\
\text { informação/ Comunicação }\end{array}$ & 11 & $6 \%$ & $19 \%$ \\
\hline $\begin{array}{l}\text { Aspectos Teóricos da } \\
\text { Ciência da Informação }\end{array}$ & - & $3 \%$ & $5 \%$ \\
\hline Outros & 56 & 134 & 250 \\
\hline $\mathbf{N}^{\circ}$ de Trabalhos & & & - \\
\hline
\end{tabular}

Organização da informação = indexação, classificação e processamento, comunicação científica, recursos humanos, instrumentos e metodologias;

Informação Tecnológica = informação para a indústria e para empresa e negócios e inteligência competitiva

Informação e Contexto = prática de informação em diferentes espaços, informação e sociedade, informação e cidadania, ação cultural;

Novas Tecnologias $=$ estudos e pesquisas privilegiando o foco nas novas tecnologias de informação e comunicação.

Fonte: Anais da Reunião de 1997 e 2000, Revista Ciência da Informação: 108 artigos e comunicações do periodo 1997 à 2000.
Fica muito claro que estamos pesquisando no núcleo da área, isto é em organização da informação e suas técnicas e metodologias. Poderia ser um bom sinal; mas para uma área altamente envolvida em tecnologia da informação pode representar uma abstenção voluntária promovida por um desconhecimento involuntário destas tecnologias e do papel que desempenham para o campo. Outro foco de pesquisa é informação e contexto uma descrição das aplicações, das praticas ou ambientações da informação para diferentes áreas do conhecimento. A pesquisa em informação tecnológica é uma contextualização da informação particularizada pela importância do setor industrial/comercial, mas é também, uma área potencialmente cobiçosa, de recursos do fomento à pesquisa para pesquisas aplicadas.

$\mathrm{Na}$ verdade indicamos com a tabela o olhar dos pesquisadores da área para seus núcleos de importância. Contudo, é difícil aceitar o número de estudos apresentados na Reunião de Brasília, como sendo um indicador do número de pesquisas existentes na área. A Ciência da Informação clama por definições: do conceito de informação, do seu objeto e do que seria pesquisa em seu campo de atuação. Contribuímos aqui, com nosso conceito de informação e pesquisa.

Entendemos por definição de informação como sendo: estruturas simbolicamente significantes com a competência de gerar conhecimento para o indivíduo e para o seu meio.

Entendemos ainda que uma pesquisa é um processo orientado para expandir as fronteiras do conhecimento; representa uma investigação ordenada e original que é coerente com uma linha de pensamento conceitual e teórica; segue em sua intenção de mostrar evidências, um método racional de ação e experimentação e tem sempre a intenção de descobrir novas informações ou desenvolver novos processos de transformação para produtos e serviços de informação.

Uma pesquisa possui assim os ingredientes básicos:

- tem intenção de produzir novo conhecimento; 
- é uma investigação ordenada, racional e original;

- tem uma base conceitual evidente, claramente explicada;

- possui um caminho claro, preciso e racional para atingir sua meta;

- possui um caminho claro, preciso e racional para atingir sua meta;

- uma pesquisa, em uma área interdisciplinar, não pode simplesmente transpor teorias e conceitos emprestados de outra área de conhecimento para a Ciência da Informação. Esta transmutação de idéias, métodos, do pensar em si teve que respeitar as características existentes e manifestas da área de Ciência da Informação, do objeto informação em si, com toda as suas condições, características e singularidades. Assim, toda uma argumentação deve ser construída para, mostrar as qualidades e a viabilidade desta transferência de teorias, conceitos e metodologias que, precisa estar clara e convincente; deve estar detalhadamente explicito e explicado como este pensar ou esta metodologia "estrangeira" se insere no mundo da Ciência da Informação.

Em nosso entender, a construção de uma base de dados, uma metodologia ou um produto de infor mação, não seria uma pesquisa mas poderia aparecer como sub-produto ou insumo de uma pesquisa.

Definimos o objeto da ciência da informação como: a ciência que se preocupa com os princípios e práticas da produção(criação), organização $e$ distribuição da informação, assim como, com o estudo dos fluxos da informação, desde sua criação até a sua utilização, e a sua transmissão ao receptor em uma variedade de formas, através de uma variedade de canais. ${ }^{11}$
$\mathrm{Na}$ verdade não acredito que seja possível enunciar objetivos ou disciplinas com permanência definitiva, para uma estruturação adequada na área de Ciência da Informação. Esta é uma área de estudo especial, pois tem um forte aspecto operacional e, muitas vezes, conceitualmente dependente de uma tecnologia intensa, com elevado teor de inovação e em contínua mutação.

Muitos de seus objetivos são também tecnologicamente dependentes e em alguns momentos se modificam ou se redefinem, envelhecem, são substituídos.

As medidas de recuperação e precisão, por exemplo, da maneira como foram enunciadas no final da década de 60, para avaliar, o armazenamento e a recuperação de conjuntos de documentos e diferentes linguagens de indexação, não existem mais. Estas medidas foram operacionalizadas em sistemas de tempo linear e espacialmente unidirecionados, foram um importante objetivo, técnica e conceitualmente, em sua época. Hoje não fazem qualquer sentido, envelheceram foram redefinidos por outros modelos tecnológicos, outros direcionamentos que a área teve que seguir. São uma importante parte da historia da ciência da informação, nada mais.

Os objetivos da ciência da informação se inscrevem em realidades diferenciadas. Como indicamos anteriormente toda a realidade se reduz a três mundos $^{12}$ : o mundo subjetivo dos sistemas cerebrais, o mundo objetivo dos sistemas materiais, e o mundo cibernético. Em nossa interpretação, são realidades da Ciência da Informação o mundo subjetivo dos conteúdos de informação, da sua geração e assimilação, o mundo objetivo dos aparatos, equipamentos e instrumentos com que opera a ciência da informação, e o mundo do ciberespaço, da velocidade igual ao infinito, do tempo e espaço zero. Como na Figura 1:

11. Inspirados em definição institucional do Instituteof Information Science de Londres, Inglaterra. Guisa.

12. ARENDT, H. A Vida do Espírito. O pensar, o querer, o julgar, Relume-Dumara, Rio, 1991. 


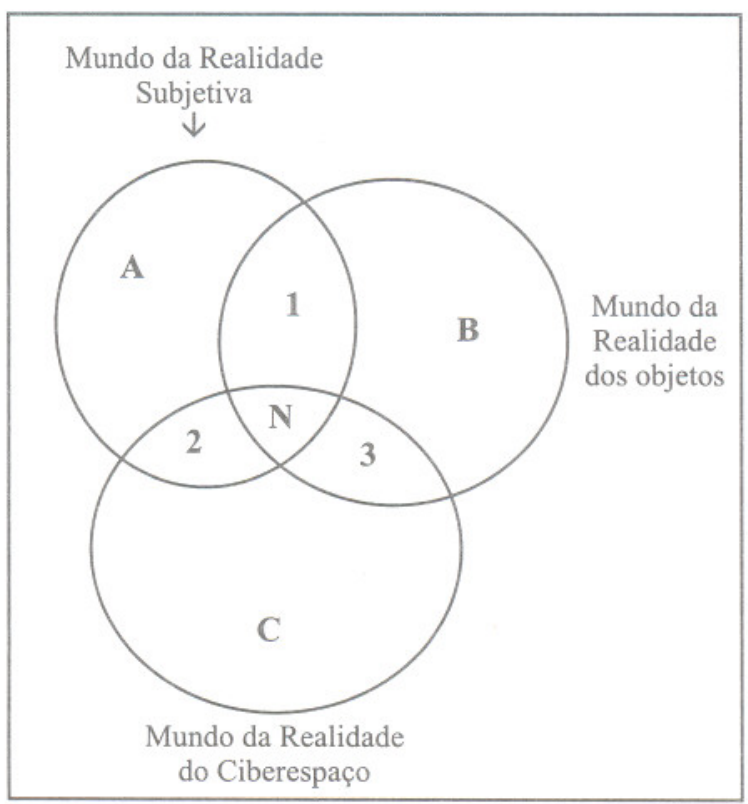

\begin{tabular}{|l|l|}
\hline \multicolumn{1}{|c|}{$\begin{array}{c}\text { Mundos da } \\
\text { Informação }\end{array}$} & \multicolumn{1}{c|}{ Exemplos } \\
\hline A-realidades subjetivas & $\begin{array}{l}\text { espaço das construções teóricas, dos } \\
\text { conteúdos, dos processos de geração, } \\
\text { interpretação e apropriação da } \\
\text { informação. }\end{array}$ \\
\hline B-realidade dos objetos & $\begin{array}{l}\text { espaço dos artefatos, dos sistemas } \\
\text { materiais, do computador, da } \\
\text { telecomunicação. }\end{array}$ \\
\hline $\begin{array}{l}\text { C-realidade do } \\
\text { ciberespaço }\end{array}$ & $\begin{array}{l}\text { o espaço dos símbolos cibernéticos, } \\
\text { da interação entre os individuos e as } \\
\text { máquinas. }\end{array}$ \\
\hline espaço de A com B & $\begin{array}{l}\text { espaço das tecnologias de informação } \\
\text { e comunicação, dos estoques de } \\
\text { conteúdos, e das redes. }\end{array}$ \\
\hline espaço de A com C & $\begin{array}{l}\text { espaço das construções dos agentes } \\
\text { inteligentes para interação do homem } \\
\text { com a máquina, os softwares. }\end{array}$ \\
\hline espaço de B com C & $\begin{array}{l}\text { espaços dos processos de telecomu- } \\
\text { nicação e das redes interativas. }\end{array}$ \\
\hline $\begin{array}{l}\text { espaço N de reunião } \\
\text { de A,B,C }\end{array}$ & $\begin{array}{l}\text { espaço das atividades de interati- } \\
\text { vidade, da interconectividade, a inteli- } \\
\text { gência artificial, da realidade virtual, e } \\
\text { dos novos desenvolvimentos. }\end{array}$ \\
\hline
\end{tabular}

Creio que, os objetivos e a abrangência da Ciência da Informação pertencem a estes diferentes mundos e às suas interações. Estes objetivos se modificam de acordo com o deslocamento de apenas um dos mundos que citamos e da velocidade com que mudam as realidades que definem cada um destes mundos. A importância relativa da Ciência da Informação, dentro de determinado tempo, estará indicada pela prioridade que os atores deste campo colocam na sua percepção de valor, das intersecções e dos espaços delineados pelos três mundos da informação.

É na articulação destes espaços mundos, em suas prioridades, que estão localizadas: a pesquisa, o ensino e a atuação profissional na Ciência da Informação.

\section{REFERENCIA BIBLIOGRÁFICA}

BARTHES, R. A morte do autor, em O Rumor da Língua, Edições 70: Lisboa, 1987

BLOOR, D. Poppers Mystyfication of Objective Knowledge, Science Studies 4, pp. 65-76, 1974.

BOULDING, K. Knowledge and Life in the Socity, University of Michigan Pres: USA, 1960.

BOURDIEU, P. O Poder Simbólico, Bertrand: Rio,1989.

BUTCHER, H.J. A inteligência Humana, Perspectiva: São Paulo, 1968.

FARRADANE, J. Relational Indexing and Classification in the Light of Recent Experimental work in Psychology, Information Storage and Retrieval, v. 1, pp. 3-11, 1963.

FARRADANE, J. Knowlwdge, Information and information Science, Journal of Information Science,v. 2, n. 2, 1980 .

FARRADANE, J. The Nature of Information, Journal of Information Science, v. 1, n. 3, 1979.

FRANCK, S. e MEHLER, J. (ed.). Cognition on Cognition. MIT Press: USA,1994.

GARDNER, H. The Minds New Science: A history of the cognitive revolution, Basic Books: USA, 1987.

ONG, W.J. Orality and Literacy: The Thechnologizing of the Word, Terence Hawkes: New York, 1988. 